\title{
Quantitative Determination of Secondary Metabolites and Antibacterial Activity of Mimosa Pudica
}

\author{
Ahamefula Anselm Ahuchaogu ${ }^{1 *}$, Okoronkwo Joseph Chukwu², A I. Obike ${ }^{1}$, \\ Tochukwu ugonna oha ${ }^{1}$, John Bull Onyekachi Echeme ${ }^{2}$ \\ ${ }^{1}$ Department of pure and Industrial Chemistry, Abia State University, Uturu, Nigeria. \\ ${ }^{2}$ Department of Chemistry, Michael Okpara University of Agriculture, Umudike, Umuahia, Abia State, Nigeria
}

*Corresponding Author: Ahamefula Anselm Ahuchaogu, Department of pure and Industrial Chemistry, Abia State University, Uturu, Nigeria

\begin{abstract}
The side effects and the increasing microbial resistance to synthetic drugs in the management and treatment of infections remain an issue in modern medicine, hence the increasing research in phytomedicine. Therefore in the present study, the active phytocomponents of Mimosa pudica's wholesome parts were revealed using quantitative phytochemical analysis. The antibacterial activity of the Ethanolic extract was studied using Well diffusion method. The activity was tested against Staphylococcus aureus, Enterococcus faecalis, Pseudomonas aeroginosa, Escherichia coli and Mycobacterium smegmatis at different concentrations of 25, 50 and $100 \mathrm{mg} /$ disc and the results have been illustrated.
\end{abstract}

Keywords: Mimosine, Secondary metabolites, Antibacterial, Zone of inhibition, Mimosa pudica, phytochemicals

\section{INTRODUCTION}

Medicinal properties of plants are the most precious gift of Mother Nature to Mankind. The primary benefits of using plant derived medicines are that they are relatively safer than synthetic alternatives, offering profound therapeutic benefits and affordable treatment. Various medicinal plants have been used for years in daily life to treat diseases all over the World [1]. Herbal medicine is based on the premise that plants contain natural substances that can promote health and alleviate illness [2]. The most important of these biologically active constituents of plants are alkaloids, flavonoids, tannins and phenolic compounds [3-5].

Mimosa pudica is one of such important medicinal plants. It is a creeping annual or perennial herb often grown for its curiosity value, as the compound leaves fold inward and drop when touched and reopens within minutes. It belongs to the Fabaceae family. The generic name Mimosa is derived from the Greek mimos (meaning mimic) alluding to the fact that the leaves moves in response to something moving against them. The specific epithet is taken from the Latin word pudica, meaning bashful or shrinking to contact [6]. Mimosa is a genus of about 400 species of herbs and shrubs, in the subfamily mimosoideae of the Legume family Fabaceae. The plant is native to Brazil, but is now a pan tropical weed, The species is known by numerous common names including Sensitive plant, Humble plant, Shameful plant, Touch-me-not, Chuimui, Ant-plant.

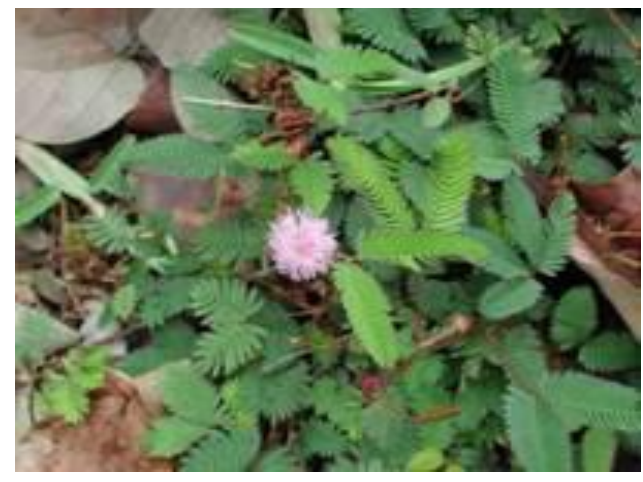

Mimosa pudica leaves and Flower 


\subsection{Vernacular- Names}

Non-English common names in three major languages in Nigeria, European language, culture areas include;

Igbo Language: Agbogho mechie ukwu.

Hausa Language: Kama walkinka.

Yoruba Language: Ewe padimo/ Patomo

In European language/ culture areas we have nao- me- toque (touch- me- not), sensitive or dormideira (roughly sleeper") in the Portuguese (with the former being more common in Portugal. Africa and Rio, dejaneiro, the middle in Sao Paulo city and the Southern capitals and the latter elsewhere in Brazil), while in Spanish, it varies in names such as mori- vivi or morivivi (DOMINICAN REPUBLIC, PUERTO RICO and other Spanish- speaking Caribbean islands, roughly translating to "I died, I lived") [7] and Dormilona (Costa Rica).

In Austronesia names vary more: in the philippines it is called makahiya, with maka-meaning "quite" or tendency to be", and -hiya meaning "shy" or "shyness", while in Tonga for example it is known as Mateloi (false death) [8], being Putri- malu (shy princess) in Indonesia and Pokok Semalu (shy plant), in Malaysia. In Sinhala (Sri Lanka) it is called Nidi kumba (sleeping plant).

In south Asia many unrelated names are also common. In Hindi it is known as chhui-mui (that which dies upon touch). In Bengali, the shrub is called lojjaboti ("that bashful girl"). In Malayalam it is called thottavaadi ("wilts by touch). In marathi it is called lazalu ("shy"). In Tamil, it is called thottasiningi ("acts when touched") and in kannada, it is known as muttidare muni ("angered by touch"). In Burmese (Myanmar) it is called hti ka yoan, which means "(crumbles when touched)". In Liberia, it is known as the picker weed [7].

This plant has a history of use for treatment of various ailments and the most commonly used plant part for this purpose is the root; but flowers, back and fruit can also be utilized. Several research works have been carried out to study about the phytochemical components of Mimosa pudica and also about the antimicrobial activity of the plant [8] Phytochemical studies on $M$. pudica have revealed the presence of alkaloids, fatty acids, non-protein amino acid (mimosine), flavonoids, C-glycosides, sterols, terpenoids, and tannins [9]. Reported major pharmacological activities are; antiviral properties, aphrodisiac properties, antimicrobial properties, anti-venom activities, anti-hepatotoxic, antioxidant effect, diuretic effect, hyperglycemic effect, and wound healing effect etc. [10]. Some of the principal bioactive compounds of interest which have been commonly associated with these therapeutic properties and disease conditions are shown in Figure 1.

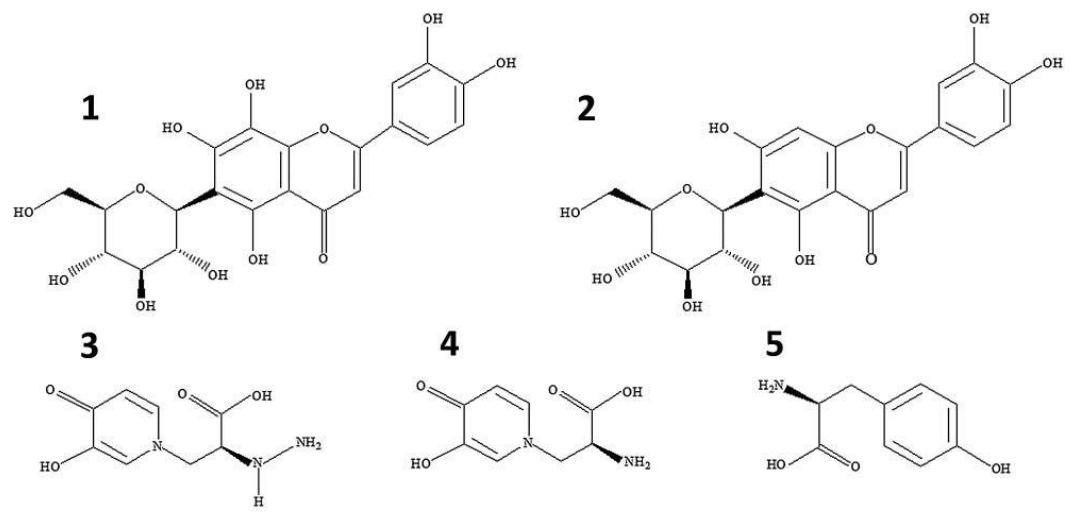

Figure1. Structures of therapeutic compounds of interest in Mimosa pudica: (1) 3,4,7,8-tetrahydroxyl- $\beta$-Dglucopyranosyl flavone, (2) 3,4,5,7-tetrahydroxyl- $\beta$-D-glucopyranosyl flavone, (3) mimosine amine, (4) mimosine, (5) tyrosine. [11].

Other isolated secondary metabolites from $M$. pudica are bufadienolide, D-pinitol, norepinephrine, P-

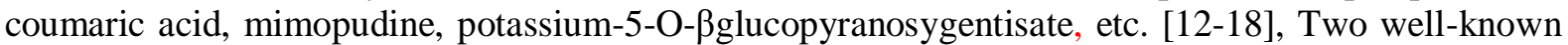
movements are observed in $M$. pudica: one is the very rapid movement of the leaves when it is stimulated by touch, heat etc, and the other is the very slow, periodical movement of the leaves called nyctinastic movement which is controlled by a biological clock [19]. The present study intends to study about the antibacterial activity of the Ethanolic extracts from Mimosa pudica against selected bacterial and as well determine quantitatively its phytochemical composition in order to support its uses in traditional medicine in South East of Nigeria. 


\section{Materials AND Methods}

\subsection{Sample Collection and Extraction}

Fresh and wholesome parts of Mimosa pudica were collected during the month of October 2016, from Ndi-Ojigwe compound in Okoko Item, Bende Local Government Area of Abia State,Nigeria. The plant was identified and authenticated by Mr. I. Ndukwe in plant taxonomy section, forestry Department of Michael Okpara University of Agriculture Umudike, Nigeria. The fresh plant materials were dried under shade to prevent interference of uv-radiation from the sun. $2 \mathrm{~kg}$ of the milled sample was percolated in $98 \%$ ethanol for 48 hours. Thereafter, it was filtered through Whatmann Filter Paper (NO 42). The filtrate was concentrated using the Digital Heidolph Rotary-evaporator (4000 series) to a crude extract of $48.9 \mathrm{~g}$.

\subsection{Phytochemical Determination}

Two grams of sample was defatted with $100 \mathrm{ml}$ of diethylether.

The phytochemical compounds including: alkaloids, saponins, flavonoids, tannins, phenols, anthocyanin and gyanogenic glycosides were carried out using method of Harbone.[20]

\subsection{Antimicrobial Activity of Extracts of Mimosa Pudica}

\subsubsection{Preparation of Extract Stock Solution}

A stock of extract was prepared by dissolving $0.2 \mathrm{~g}(200 \mathrm{mg})$ of the plant extract in $2.0 \mathrm{ml}$ of dimethylsulphoxide (DMSO) to get a concentration of $100 \mathrm{mg} / \mathrm{ml}$ of the stock solution. This stock solution was diluted with sterile distilled water to give concentration of $50 \mathrm{mg} / \mathrm{ml}$ and $25 \mathrm{mg} / \mathrm{ml}$.

\subsubsection{Test Micro-Organisms}

The strains of microorganisms used (Staphylococcus aureus ATCC 25923; Enterococcus faecalis ATCC 7080; Pseudomonas aeruginosa ATCC 27853; Escherichia coli ATCC 25922 and Mycobacterium smegmatis ATCC 19420) were purchased from the American Type Culture Collection (ATCC, USA). The Type Culture organisms were maintained on Nutrient agar slants after reactivation on Nutrient agar plates. The Nutrient agar medium used was from Biomark Laboratories, India. A cell suspension of each microorganism was prepared by transferring colonies from the nutrient agar plate to turbidity standard tube No. 0.5 with sterile normal saline.

\subsubsection{Preparation of Discs}

Filter paper discs (Whatman No. 1) were sterilized in hot air oven inside glass Petri dishes at $160{ }^{\circ} \mathrm{C}$ for 2 hours. Each disc was impregnated with $20 \mu \mathrm{l}$ of the plant extract solution at the various concentrations of $25 \mathrm{mg} / \mathrm{mL} 50 \mathrm{mg} / \mathrm{mL}$ and $100 \mathrm{mg} / \mathrm{mL}$ and labeled accordingly. The discs were placed in an incubator at $40{ }^{\circ} \mathrm{C}$ and left for 2 hours to dry. They were used immediately and the remaining was stored at $4{ }^{\circ} \mathrm{C}$. Similarly, discs of chloramphenicol and DMSO were also prepared as control.

\subsubsection{Disc Diffusion Test}

This was performed following the Kirby- Bauer method. Plates of Mueller Hinton Agar (MHA, Hardy Diagnostics, USA) were prepared according to manufacturer's instructions. The plates were dried in an incubator at $40{ }^{\circ} \mathrm{C}$ for $30 \mathrm{~min}$. using a sterile swab stick, standardized cells suspension containing an inoculums size of $5 \times 10^{8 \mathrm{CFU}} / \mathrm{ml}$ was aseptically spread on the agar surface. The discs of the extracts and antibiotics were placed on the inoculated plates of each test organisms. The plates were incubated at $35-37{ }^{\circ} \mathrm{C}$ for $16-18$ hours. The diameter of any clear zone of inhibition obtained around the discs was measured manually using a transparent ruler. The experiment was replicated three times for each extract and antibiotic.

\section{RESULTS AND DISCUSSION}

Table1. Percentage composition of phytochemicals in Mimosa pudica

\begin{tabular}{|l|l|}
\hline Constituent & $\mathbf{( \% )}$ \\
\hline Alkaloid & $9.05 \pm 0.098$ \\
\hline Flavonoid & $8.23 \pm 0.16$ \\
\hline Steroid & 2.490 .021 \\
\hline Saponin & $8.15 \pm 0.09$ \\
\hline Phenol & $1.02 \pm 0.05$ \\
\hline Tannin & 0.0830 .00014 \\
\hline Cyanogenic-glycoside & $0.122 \pm 0.0028$ \\
\hline Anthocyanin & $1.913 \pm 0.126$ \\
\hline
\end{tabular}

Result based on mean \pm standard deviation of triplicate sampling measurements. 
The quantitative estimation of the percentage of phytochemicals contain in Mimosa pudica in the present study is summarized in table 1. The whole plant consist of alkaloid $9.05 \%$, flavonoid $8.32 \%$, steroid $2.49 \%$, saponin $8.15 \%$, phenol $1.02 \%$, tannin $0.083 \%$, cyanogenic glycoside $0.122 \%$ and anthocyanin $1.913 \%$. Alkaloids are the most efficient phytochemical compound. True isolated alkaloids and the synthetic derivatives are used as the basic medicinal compounds because of their analgesic, anti-spasmodic and bacterial properties [27]. The presence of tannins and phenols in the plant can attest to its use for healing of wounds, hemorrhoids in herbal medicine [28]).

The plant also contains an appreciable amount of flavonoids. The biological functions include protection against allergies inflammation, platelets aggregation, and microbes. Flavonoids through their free radical and scavenging property tend to lower cholesterol level and reduce the risk of heart attack [29]. Flavonoids have multiple biological activities that include estrogenic effect as well as inhibiting the action of some enzymes [30].

\subsection{Antimicrobial Activity of Extract of Mimosa Pudica}

Table2. Zone of Inhibition ( $\mathrm{mm}$ ) produced by Crude Ethanol extracts against the Test Organisms

\begin{tabular}{|l|l|l|l|l|}
\hline Organisms & \multicolumn{3}{|l|}{$\begin{array}{l}\text { Concentration } \\
\text { (mg/ml) }\end{array}$} & $\begin{array}{l}\text { Control Antibiotic (Chloramphenicol) } \\
\mathbf{1 0 0 m g / m L}\end{array}$ \\
\hline & $\mathbf{2 5}$ & $\mathbf{5 0}$ & $\mathbf{1 0 0}$ & \\
\hline Staphylococcus aureus (ATCC 25923) & $\mathbf{3 . 5}$ & $\mathbf{7 . 0}$ & $\mathbf{9 . 8}$ & 30.0 \\
\hline Enterococcus faecalis (ATCC 7080) & $\mathbf{0 . 0}$ & $\mathbf{0 . 0}$ & $\mathbf{0 . 0}$ & 30.6 \\
\hline Pseudomonas aeroginosa (ATCC 27853) & $\mathbf{1 2 . 0}$ & $\mathbf{1 4 . 5}$ & $\mathbf{1 8 . 0}$ & 31.0 \\
\hline Escherichia coli (ATCC 25922) & $\mathbf{5 . 5}$ & $\mathbf{1 0 . 6}$ & $\mathbf{1 4 . 0}$ & 30.0 \\
\hline Mycobacterium smegmatis & $\mathbf{0 . 0}$ & $\mathbf{0 . 0}$ & $\mathbf{0 . 0}$ & 19.3 \\
\hline
\end{tabular}

ATCC $=$ American Type Culture Collection

The result of the antimicrobial assay of the Ethanol extract of Mimosa pudica shown in table 2 indicated that the plant exhibited antibacterial activity against

Staphylococcus aureus, Pseudomonas aeroginosa and Escherichia coli at three different concentrations of $25 \mathrm{mg}, 50 \mathrm{mg}$ and $100 \mathrm{mg} /$ disc. The inhibitory effect is stronger on Pseudomonas aeroginosa than on Staphylococcus aureus and Escherichia coli at low concentration of $25 \mathrm{mg}$ as indicated in table 2. The extract did not show any level of sensitivity on Mycobacterium smegmatis and Enterococcus faecalis at any of the concentrations used.

\section{CONCLUSION}

This study showed that the selected Mimosa pudica extracts have antibacterial activity against Staphylococcus aureus, Pseudomonas aeroginosa and Escherichia coli. Also from the above studies, we can see that the traditional plants may represent new sources of anti-microbial with stable, biologically active components that can establish a scientific base for the use of plants in modern medicine. Further investigation should be carried out and documented in other to isolate, purify and characterize the active compounds responsible for the antibacterial activity.

\section{REFERENCES}

[1] Nair, R., Kalariya, T. and Sumitra, C.. Antibacterial activity of some selected Indian medicinal Flora Turk. Journal of Botany.2005, 29:41-47.

[2] Balakumar,S. and Rajan .S.. Antifungal activity of Ocimum Sanctum Linn. (Lamiaceae) on clinically isolated dermatophytic fungi. Asian pacific Journal of Tropical Medicine (2011) 4(8):654-657.

[3] Kiruba et al;. Phytochemical analysis of the flower extracts of Rhododendron arboreum Sm. SSP. Nilagiricum (zenker) Tagg.Asian Pacific Journal of Tropical Biomedicine (2011) 1: 278-280.

[4] Rajan. S, S. Mahalakshmi, VM. Deepa, K. Sathya, S. Shajitha, T.Thirunalasundari Antioxidant Potentials OF Punica granatum Fruit Rind extracts International Journal of Pharmacy and Pharmaceutical Sciences 2011 3:82-88

[5] Mohana, D.C., Satish, S. and Reveesha, K.A. Antifugal activity of 2-hydroxy-4-methoxybenzaldehyde isolated from Decalpis hamiltonii (wight and arn.) on seed-borne fungi causing biodeteriotion of paddy. Journal of plant protection Research (2009) 49(3) 223-226.

[6] Barneby, R.. Sensitive censitae: a description of the genus Mimosa Linnaeus (Mimosaceae) in the New World. New York Botanical Garden, New York. (1991) 
[7] Union County College Biology Department. “The Sensitive Plant”. (2008)

[8] Churchward, C.M.. Tongan Dictionary. Tonga: Government Printing press. (1959) P. 344.

[9] Gandhiraja, N., Sriram, S., Meenna, V., Kavitha Srilakshmi, J., Sasikumar, C.,Rajeswari, R.. Phytochemical Screening and Antimicrobial Activity of the plant Extracts of Mimosa Pudica. L. Against Selected Microbes. Ethnobotanical leaflets, (2009) 13:618-24.

[10] Genest,S., Kerr, C., Shah, A., Rahman, M.M., saif-E-Nasar, G.M., Nigam, P,et al. Comparative Bioactivity of two Mimosa Species. Lat Am Caribb Bull med Aromatic plants. 2008 7:38-43.

[11] Amalraj, T. and Ignacimuthu, S. Hyperglycemic effect of leaves of Mimosa pudica Linn. Fitoterapia. 2002. 73: 351-2

[12] Chaminie B. Gunawardhana, Shakkya J. Ranasinghe \& Viduranga Y.Waisundara Review: Mimosa pudica Linn: the garden weed with therapeutic properties,Israel Journal of Plant Sciences. 2015, 62:4, 234-241.

[13] Clark - lewis, J.W., Porter., 1. j. Aus J. Chem 25, 1943. 1992

[14] Yadava R. N., Yadav's, Asian J. Chem 13, 1157. 2001

[15] Salland C, El-Turk, J, Breda C., Buffard, D., DE Kozak, I., Esnault R., Kondrosi, A., Plant Science 109. 1995

[16] Ueda, M. and Yamamura, S.. Angew. Chem. Int. Engl 39, 1400. 2000

[17] Fromm, et al; Electrical signal and their physiological significance in plants. Plant cell \& Environment. http://onlinelibrary.wiley.com/doi/10.1111/y.1365-3040.2006.01614.x/pdf. 2007

[18] Nair, L.S., Menon, S.N., Shailajan, S., Baing, M.M. and Sane, R.T. Reversed-phase-high-performancethin-layer-chromatographic quantification of mimosine from whole plant of Mimosa pudica Linn. J planar Chromatogr. 2007.20: $\quad$ 49-51

[19] Ueda, M. and Yamamura, S.). The chemistry of leaf movement in mimosa Pudica L. Tetrahedron. 55: $1999,10937-48$

[20] Harbone J B. Phytochemical Method, Chapman and Hall London.1973,110-113

[21] Corthout, J., Pieters, L.A., Claeys, M., Vanden Berghe, D.A. and Viletink, A. J. Anti-viral caffeoyl esters from Spondias mombin. Planta Medica. 1994. 60: 460-463.

[22] De Ferreyra EC. Planta que curan las heridas del hombre y loss animals. Boletin de lima 1-12. In: villages et all: evaluation of the wound healing activity of selected traditional medicinal plants from peru. Journal of ethnopharmacology. 1981 55:193-200.

[23] Salah,W., Miller, N., Pagauga, G., Tybury, E., Bolwell, E, Rice and Evans, C. Polyphenolic flavonoids as scavenger of aqueous phase radicals and Chain breaking antioxidants. Arch. Biochem. 1998. 2: 239-346

[24] Middleton, E. and Kandswani, H.. Effects of flavonoids on immune and inflammatory functions, biochemistry and pharmacology, 1992.43: 1167-1172.

Citation: A. Anselm Ahuchaogu, "Quantitative Determination of Secondary Metabolites and Antibacterial Activity of Mimosa Pudica", International Journal of Medicinal Plants and Natural Products (IJMPNP), vol. 3, no. 2, pp. 1-5, 2017. http://dx.doi.org/10.20431/2454-7999.0302001

Copyright: (c) 2017 Authors. This is an open-access article distributed under the terms of the Creative Commons Attribution License, which permits unrestricted use, distribution, and reproduction in any medium, provided the original author and source are credited. 